Abstracta Iranica

Revue bibliographique pour le domaine irano-aryen

Volume 34-35-36 | 2017

Comptes rendus des publications de 2011-2013

\title{
Touraj Daryaee (ed.). Cyrus the Great. An Ancient Iranian King
}

\section{Rémy Boucharlat}

\section{(2) OpenEdition}

1 Journals

\section{Édition électronique}

URL : http://journals.openedition.org/abstractairanica/42137

DOI : 10.4000/abstractairanica.42137

ISSN : 1961-960X

Éditeur :

CNRS (UMR 7528 Mondes iraniens et indiens), Éditions de l'IFRI

Référence électronique

Rémy Boucharlat, «Touraj Daryaee (ed.). Cyrus the Great. An Ancient Iranian King », Abstracta Iranica [En ligne], Volume 34-35-36 | 2017, document 120, mis en ligne le 30 juillet 2017, consulté le 03 octobre 2020. URL : http://journals.openedition.org/abstractairanica/42137 ; DOI : https://doi.org/10.4000/ abstractairanica.42137

Ce document a été généré automatiquement le 3 octobre 2020.

Tous droits réservés 


\title{
Touraj Daryaee (ed.). Cyrus the Great. An Ancient Iranian King
}

\author{
Rémy Boucharlat
}

\section{RÉFÉRENCE}

Touraj Daryaee (ed.). Cyrus the Great. An Ancient Iranian King. Santa Monica, Afshar Publishing, 2013, XV-98 p., ill., index.

1 Ce petit livre de circonstance a été édité à l'occasion de l'exposition du Cylindre de Cyrus, prêté par le British Museum à plusieurs musées des Etats-Unis en 2013. Il n'apporte pas d'idées nouvelles, mais constitue une introduction commode sur Cyrus, sa vie et son œuvre, sous la forme de cinq articles, rédigés par des spécialistes incontestables, suivis de traductions du Cylindre :

2 P. Briant, "Cyrus the Great ", rappelle son histoire, celle de ses conquêtes, mais souligne son rôle d'administrateur du nouvel empire ;

3 T. Daryaee, « Religion of Cyrus the Great » reconnaît que le très peu que nous savons de la religion de Cyrus correspond à des pratiques iraniennes, mais ne se prononce pas sur son mazdéisme ;

4 A. Mousavi, « Pilgrimage to Pasargadae » expose l'histoire de la recherche sur le site jusqu'à E. Herzfeld et rappelle le rôle majeur de G.N. Curzon pour son identification ;

5 M.W. Stolper, "The Form, Language and Contents of the Cyrus Cylinder " analyse le texte et le replace dans la production des textes royaux mésopotamiens ;

6 D. Stronach, "Cyrus and Pasargadae » présente les vestiges archéologiques et les recherche de terrain depuis E. Herzfeld. Suivent la traduction du texte du Cylindre en anglais par I. Finkel (cf. son livre, The Cyrus Cylinder, 2013) et celle en persan par Sh. Razmjou. 


\section{AUTEURS}

\section{RÉMY BOUCHARLAT}

UMR 5133 CNRS-Université de Lyon 